\title{
A CONSTRUÇÃO DA AUTONOMIA MORAL: A CONTRIBUIÇÃO DA TEORIA DO DESENVOLVIMENTO DO EGO DE JANE LOEVINGER ${ }^{1}$
}

\author{
Maria Luísa Branco ${ }^{2}$ \\ Universidade da Beira Interior - Portugal
}

\begin{abstract}
Resumo: A autonomia moral foi, desde os primórdios do pensamento ocidental, entendida como expoente da maturidade humana. No contexto da tradição cognitivo-desenvolvimental, a construção da autonomia é concebida, predominantemente, como um processo de separação-individuação. A teoria do desenvolvimento do ego de Jane Loevinger, combinando a abordagem cognitivo-desenvolvimental com a abordagem psicanalítica, propõe o entendimento da autonomia moral como resultado de uma dialética de separação-inclusão, favorecendo uma compreensão mais adequada deste fenômeno, enquanto manifestação de uma maturidade socioafetiva.
\end{abstract}

Palavras-chave: autonomia moral; tradição cognitivo-desenvolvimental; desenvolvimento do ego; Loevinger.

\section{THE CONSTRUCTION OF MORAL AUTONOMY: JANE LOEVINGER'S EGO DEVELOPMENT THEORY CONTRIBUTION}

\begin{abstract}
Since the beginnings of occidental reflection, moral autonomy was considered as a sign of human maturity. According to the cognitive-developmental tradition, the construction of moral autonomy is mainly a process of separation- individuation. The ego developmental theory of Jane Loevinger, combining the cognitive developmental and the psychoanalytic approaches, propose an understanding of moral autonomy as the result of a separation-inclusion movement. Therefore a more adequate comprehension of this phenomenon emerges, associated to a frame of socio-affective maturity.
\end{abstract}

Key words: moral autonomy; ego development; cognitive-developmental tradition; Loevinger.

A reflexão sobre a autonomia foi uma constante ao longo do pensamento ocidental. Considerou-se que era a expressão privilegiada da humanidade do homem e a consagração da sua realidade constitutivamente moral. A moralidade é uma necessidade no homem, exigida pelas suas próprias estruturas biopsicológicas e a autonomia moral é o resultado tornado possível por esta hiperformalização do ser humano. Enquanto expoente do desenvolvimento pessoal, a autonomia foi, desde sempre, entendida como estando associada a um quadro de maturidade global.

\footnotetext{
${ }^{1}$ Artigo recebido para publicação em 21/11/02; aceito em 04/02/03. ${ }^{2}$ Endereço para correspondência: Maria Luísa Branco, Departamento de Psicologia e Educação, Universidade da Beira Interior, Pólo IV, Estrada do Sineiro, s/n, 6200, Covilhã, Portugal, Email: lbranco@ubi.pt
}

Em contexto psicológico, a autonomia pode ser entendida na acepção emocional, comportamental e moral. Embora tendo em conta a interrelação entre estas três dimensões da autonomia, no presente texto debruçar-nos-emos sobre a autonomia moral. Nesta perspectiva, entendemos por ser autônomo a capacidade de estabelecer preferências e prioridades e um dar-se normas, com base na construção de uma perspectiva própria. Na idéia de indivíduo autônomo, como ser que se singulariza, radica a idéia da existência como projeto único, cuja particularidade é confirmada no reconhecimento e respeito pelas outras existências como projetos únicos e singulares. Considera-se, pois, que a construção da autonomia de cada um só pode ser verdadeiramente levada a cabo num contexto facilitador da autonomia de todos. 


\section{Maria Luísa Branco}

No campo da psicologia, o conceito de autonomia emerge da consideração do fenômeno do desenvolvimento. $\mathrm{O}$ estudo das mudanças de comportamento, nos seus mais variados aspectos (perceptivo, intelectual, afetivo, moral, social, etc) ocorridas ao longo do tempo configura um domínio específico que é o da a psicologia do desenvolvimento. No presente artigo analisaremos a construção da autonomia moral, no âmbito da psicologia do desenvolvimento, à luz dos dados da tradição cognitivodesenvolvimental, salientando a contribuição da teoria do desenvolvimento do ego de Jane Loevinger para a compreensão daquele fenômeno.

\section{A Teoria de Jean Piaget: Heteronomia e Autono- mia Morais}

A tradição cognitivo-desenvolvimental tem origem na obra de Jean Piaget. O pressuposto básico desta corrente psicológica é o de que a construção das estruturas mentais resulta da interação entre tendências estruturais próprias do sujeito e a estrutura do mundo exterior. Nesta interação radicam os estágios cognitivos, que não são mais do que as transformações progressivas que aquelas estruturas sofrem mediante assimilações e acomodações sucessivas, com vista à manutenção do equilíbrio psicológico (Piaget, 1975). Os estágios cognitivos representam, como tal, diferentes formas de pensamento, formando entre si uma sequiência invariável no desenvolvimento individual. A cada estágio há subjacente uma organização própria do pensamento que se manifesta em todas as tarefas com as quais o sujeito é confrontado, evidenciando, pois, uma tendência estrutural. A teoria cognitivo-desenvolvimental salienta a importância do componente cognitivo em todos os comportamentos e suas mudanças seqüenciais.

Tendo embora concentrado os seus esforços na compreensão do desenvolvimento cognitivo, Piaget (1932) debruçou-se igualmente sobre o desenvolvimento dos conceitos morais e sociais. Segundo este autor, o pensamento e os sentimentos desenvolvem-se de forma paralela, constituindo o desenvolvimento cognitivo como uma condicionante da forma de sentir e do juízo moral.

Tal como o desenvolvimento da inteligência, o desenvolvimento do juízo moral processa-se da heteronomia para a autonomia. A heteronomia representa, no plano moral, o paralelo do egocentrismo intelectual primitivo, no qual radica. A impossibilidade de compreender as regras e os valores morais no sentido dos adultos, conduz a criança, nos estádios sensório-motor e pré-operatório, a equacionar aquelas como sagradas e absolutas. A bondade de um comportamento radica na submissão às regras estabelecidas por uma autoridade adulta exterior e no fato de não acarretar uma punição da mesma. $\mathrm{O}$ castigo e a sua ausência são os critérios que permitem distinguir, nesta fase, o bom e o mau. Estamos aqui no nível da subjetividade mais primitiva que não se interiorizou. A confusão entre o subjetivo e o objetivo, característica do realismo conceptual próprio dos estágios cognitivos menos elevados, prolonga-se no realismo moral (as regras e os valores são concebidos como entidades absolutas, que emanam de uma auttoridade adulta aos quais é necessário obedecer incondicionalmente). Central no desenvolvimento da autonomia moral é, então, o fenômeno da cooperação entre pares, coincidente com o desenvolvimento das operações concretas. O sujeito começa a ser capaz de perspectivar as situações segundo outros pontos de vista, o que corresponde ao declínio do egocentrismo intelectual. Esta cooperação acarreta, assim, o fenômeno da reciprocidade. A criança interioriza as regras morais, compreendendo a sua necessidade $\mathrm{e}$ apercebendo-se progressivamente da sua relatividade (modificabilidade segundo o contexto). $\mathrm{O}$ critério de bondade de uma ação desloca-se das suas consequiências materiais (objetividade) para a intenção que lhe preside (subjetividade).

O respeito mútuo sucede-se, assim, ao respeito unilateral. A consideração da pura igualdade é substituída pela consciência de uma forma superior de igualdade e de reciprocidade, traduzida no conceito de equidade (relação de reciprocidade que leva em conta a situação específica de cada indivíduo, exigindo como condição necessária o alcance das operações formais). A experiência da igualdade $e 0$ exercício da cooperação são, então, os fatores essenciais que permitem o acesso à autonomia.

O movimento de descentralização, conducente à autonomia, equivale à fundação da personalidade, que pressupõe a consideração e subordinação a um elemento ideal, apropriado pelo próprio indivíduo, 
fundamento do respeito mútuo e da cooperação. É importante realçar que, segundo Piaget, não é possível falar em estágios morais, dado que uma criança predominantemente autônoma pode evidenciar aspectos heterônomos e vice-versa, daí a sua preferência pelo termo fases.

\section{A Teoria de Lawrence Kohlberg : 0 Carácter Estrutural do Desenvolvimento Moral}

As investigações de Lawrence Kohlberg vêm no prolongamento da obra de Piaget, consistindo na aplicação do quadro conceptual definido por este autor ao desenvolvimento moral. Kohlberg considera que é possível detectar, na área do desenvolvimento da personalidade social, a existência de estágios ou mudanças estruturais, que acompanham os estágios cognitivos. Os conceitos de conflito, descentração e equilibração são retomados para explicar a influência do meio social sobre o desenvolvimento moral (Kohlberg,1982).

Kohlberg definiu seis estágios do desenvolvimento moral, usando como metodologia a aplicação de dilemas morais hipotéticos, solicitando uma resposta livre. Cada estágio representa uma definição própria dos conceitos morais básicos, sendo possível estabelecer entre eles uma seqüência hierárquica de progressiva diferenciação e integração. Os tipos superiores de pensamento moral integram e substituem os in- feriores. Cada estágio consiste, assim, num processo ativo de organização do mundo, correspondendo a uma totalidade estruturada. Isto significa que, quando confrontados com vários aspectos do juízo moral, os sujeitos evidenciam sempre uma mesma lógica, que é a do respectivo estágio em que se situam. Estes estágios são universais e definitivos; verificam-se em todas as culturas e sucedem-se segundo uma seqüência invariável. Uma vez atingido um estágio superior não há retrocesso. A progressão nos estágios equivale a uma marcha para o equilibrio.

\section{Os estágios de desenvolvimento moral e a constru- ção da autonomia moral}

O raciocínio moral é essencialmente um processo de tomada de perspectiva, assumindo, em cada estágio, uma nova estrutura lógica paralela à dos estágios de Piaget e que é uma estrutura de justiça, progressivamente mais compreensiva, diferenciada $\mathrm{e}$ equilibrada (Kohlberg, 1981). Os estágios de desenvolvimento moral traduzem, pois, formas cada vez mais elaboradas e racionais de justificar as decisões e de solucionar os conflitos.

Kolhberg considera três níveis gerais de desenvolvimento moral, cada um dos quais subdividido em dois estágios. O Quadro 1 traz um resumo dos estágios.

Quadro 1: Estágios de Desenvolvimento Moral de Kohlberg

\begin{tabular}{|c|c|c|}
\hline O QUE É JUSTO & PORQUE & PONTO DE VISTA SOCIAL \\
\hline \multicolumn{3}{|c|}{ NIVEL PRE-CONVENCIONAL } \\
\hline $\begin{array}{c}\text { Estágio I } \\
\text { Obedecer, evitar a punição (ou os } \\
\text { danos físicos e materiais). } \\
\text { Estágio } 2 \\
\text { Obedecer às regras que servem o } \\
\text { interesse próprio. } \\
\text { Nas partilhas e justo o que é igual. }\end{array}$ & $\begin{array}{l}\text { Superioridade dos pais, do adulto, ou } \\
\text { daqueles que castigam. } \\
\text { Porque cada um segue o seu próprio } \\
\text { interesse. }\end{array}$ & $\begin{array}{l}\text { Egocentrismo. O ponto de vista do } \\
\text { outro não é considerado. } \\
\text { Embora os pontos de vista possam } \\
\text { ser diferentes, o ponto de vista } \\
\text { próprio continua a ter a primazia. }\end{array}$ \\
\hline \multicolumn{3}{|c|}{ NIVEL CONVENCIONAL } \\
\hline $\begin{array}{c}\text { Estágio } 3 \\
\text { Fazer o que os outros (em particular } \\
\text { os mais proximos) esperam. Ser bom, } \\
\text { demonstrar interesse pelos outros, } \\
\text { respeita-los, confiar neles, ser leal. } \\
\text { Estágio } 4 \\
\text { Cumprir os seus deveres e seguir as } \\
\text { leis, mesmo quando estas entram em } \\
\text { conflito com as regras sociais. }\end{array}$ & $\begin{array}{c}\text { Porque é necessário colocar-se no } \\
\text { lugar dos outros. É necessário manter } \\
\text { os comportamentos socialmente } \\
\text { aprovados. } \\
\text { Porque é necessário manter as } \\
\text { instituições e evitar os desequilíbrios } \\
\text { que adviriam se "toda a gente fizesse } \\
\text { assim". }\end{array}$ & $\begin{array}{l}\text { O individuo tenta colocar-se no lugar } \\
\text { dos outros, mas sem considerar um } \\
\text { sistema de perspectivas geral. } \\
\text { Tomada de consciência das intençðes } \\
\text { dos outros, dos acordos e dos } \\
\text { desacordos. } \\
\text { Os indivíduos são considerados em } \\
\text { função da posição que ocupam na } \\
\text { sociedade. } \\
\text { Não há conflito lei-moral. }\end{array}$ \\
\hline
\end{tabular}




\begin{tabular}{|c|c|c|}
\hline Estágio 5 & NÍVEL POS-CONVENCIONAL \\
\hline $\begin{array}{c}\text { Distinção entre valores individuais e } \\
\text { direitos elementares, tais como a vida } \\
\text { e a liberdade. }\end{array}$ & $\begin{array}{c}\text { Porque temos deveres decorrentes de } \\
\text { um contrato social que visa a } \\
\text { realização do bem para o maior } \\
\text { número. }\end{array}$ & $\begin{array}{c}\text { Visão igualitária (igualdade de } \\
\text { oportunidades). Lei e moral podem } \\
\text { entrar em conflito. }\end{array}$ \\
$\begin{array}{c}\text { Estágio 6 } \\
\text { dignualdade e o respeito pela } \\
\text { princípios morais universais. } \\
\text { Suscitam uma adesão livre. }\end{array}$ & $\begin{array}{c}\text { Porque os princípios morais são } \\
\text { universais e há que se comprometer } \\
\text { na sua defesa. }\end{array}$ & $\begin{array}{c}\text { Os indivíduos são fins em si e devem } \\
\text { sẹr considerados como tais. }\end{array}$ \\
\hline
\end{tabular}

Fonte: Moessinger (1989)

Segundo este autor, os conflitos de valores podem ser racionalmente solucionáveis, dado que é possível tender para um conjunto de princípios éticos universais. O conflito de valores é apenas uma etapa do diálogo que visa atingi-lo com um acordo universal, no nível de uma generalidade superior (pelo reconhecimento de princípios éticos universais). Assim, a autonomia moral é alcançada nos dois últimos estágios de desenvolvimento moral, traduzindo-se numa racionalização de ideais, fruto da interação do indivíduo com o meio social.

A importância dos vários grupos sociais (entre os quais a escola) é salientada na criação de oportunidades de descentralização social, que permitindo aos indivíduos a apreciação de outras perspectivas e o colocar-se no papel do outro, favorecem o desenvolvimento moral. Assim como o egocentrismo intelectual e moral da criança caracteriza a moralidade autônoma, também o estar voltado para a perspectiva do outro é inseparável da autonomia. Através dela, o pensamento realiza a sua natureza relacional.

\section{A Superação da Tradição Cognitivo- Desenvolvimental: As Teorias do Desenvolvimento do Ego}

A perspectiva cognitivo-desenvolvimental, na sua formulação piagetiana original, caracterizava-se por ser uma aproximação exterior descritiva e com caráter epistemológico. Excluía o ponto de vista participativo, isto é, a forma como as diversas estruturações da realidade, estabelecidas ao longo do desenvolvimento, são experienciadas pelo próprio sujeito (Kegan, 1982).

A consciência das potencialidades e das limitações da teoria de Piaget impeliu o diálogo com outras tradições psicológicas, nomeadamente com a psicanalítica. $O$ aprofundamento da cognição social, levado a cabo pelas teorias neopiagetianas, constituiu o elo de ligação que faltava entre estes dois paradigmas dominantes do desenvolvimento, facilitando a apropriação do conceito de ego pela aproximação estrutural.

Neste contexto, há que fazer referência à teoria de Robert Selman, que evidencia a base estrutural do conhecimento social da criança, afirmando uma sucessão de estágios de cognição social, correspondentes a níveis de perspectiva social. Segundo Selman (1980), "a cognição social não pode ser reduzida, de forma teórica ou prática, à mera aplicação simples das competências cognitivas (estrutura) à esfera social (conteúdo)" (p.14). Contudo, o desenvolvimento da cognição social implica o desenvolvimento cognitivo.

O desenvolvimento da cognição social fornece a base para o desenvolvimento social e para o comportamento da pessoa. Para Selman (1980), "a criança, em sentido geral, estrutura e compreende o seu ambiente social envolvente através da descentração social, e o raciocínio moral depende, em parte, da sua perspectiva social" (p.36).

No quadro das teorias neopiagetianas, que reclamam da perspectiva estrutural do desenvolvimento, a relação do eu com o não-eu (físico e social) oca- 
siona uma reestruturação dialética da própria unidade originária de sentido com a qual o sujeito se identifica (o próprio). Emerge desta compreensão o conceito de desenvolvimento do ego. A consideração deste conceito, e do seu desenvolvimento ao longo de um processo, corresponde à necessidade de compreensão da pessoa como um todo, ou seja, traduz uma compreensão holística que abarca as dimensões já consideradas do desenvolvimento (Blasi, 1993; Hauser, 1993).

\section{A Teoria do Desenvolvimento do Ego de Jane Loevinger}

\section{Conceito de ego e de desenvolvimento do ego}

Loevinger (1982) considera que o ego é uma entidade processual e não substantiva. A essência do ego consiste, no dizer de Loevinger (1982), no "impulso para dominar, integrar e dar sentido à experiência" (p. 59). Enquanto função organizadora ou sintética, o ego possui uma natureza estrutural. Equivale àquilo que a pessoa pensa de si mesma, como eu auto-reflexivo (próprio), nos vários momentos da sua existência. Assim, não correspondendo exatamente à totalidade da pessoa, o ego fornece, contudo, o enquadramento, constituído pelos motivos e pelos propósitos existenciais, que permite tornar una e coerente determinada pessoa. Daí o holismo inerente a esta concepção. É nesta doação de sentido que radicam as outras características específicas da personalidade. Quer dizer, a personalidade é uma estrutura, constituída pelo equilíbrio entre várias características, equilíbrio esse conferido por um determinado sentido ou busca de autoconsistência.

Assumindo a filiação estrutural piagetiana, Loevinger perspectiva o desenvolvimento do ego como um processo de transformação sucessiva de estruturas (Noam, 1993). Cada estágio de desenvolvimento evidencia uma estrutura básica ou um sentido central. Na medida em que os estágios podem ser encarados como pontos de fixação potencial, cada estágio define, assim, uma tipologia ou caracteriologia, isto é, tipos de crianças e de adultos Esta concepção é necessariamente uma abstração, dado não ser diretamente observável, proporcionando um quadro de referência que permite integrar questões várias relacionadas com o desenvolvimento.

\section{Os estágios de desenvolvimento do ego}

O desenvolvimento do ego é concebido por Loevinger (1982) de modo seqüencial. Os estágios do ego são definidos, em parte, em termos de estruturas, mas também em termos de funções e motivos, referentes à auto-valorização e defesa do próprio sujeito. Neste aspecto, Loevinger traduz a dupla influência estruturalista, de origem piagetiana e das concepções neopsicanalíticas do ego. É por este motivo que a teoria de Loevinger, embora se integre nas correntes estruturais do desenvolvimento, inclui aspectos das teorias funcionais, cuja característica fundamental consiste em encarar os processos mentais em termos das funções que exercem para o indivíduo.

Loevinger considera uma seqüência desenvolvimental de seis estágios (do Eu- 1 ao Eu-6) e três níveis de transição (Eu-delta/3; Eu-3/4 e Eu-4/ 5). Estes últimos surgiram em resultado da investigação empírica conduzida pela autora (Loevinger \& Wessler, 1970), para elaboração de um teste projetivo do desenvolvimento do ego - o Teste de Completar Frases da Universidade de Washington (Sentence Completion Test, vulgarmente referido na literatura por SCT). O Quadro 2 apresenta um resumo dos estágios de desenvolvimento do ego.

Quadro 2: Alguns Marcos no Desenvolvimento do Ego

\begin{tabular}{|c|c|c|c|c|c|}
\hline ESTADIO & CóDIGO & $\begin{array}{c}\text { CONTROLO DE } \\
\text { IMPULSO } \\
\text { DES. DE CARÁCTER }\end{array}$ & $\begin{array}{c}\text { ESTILO } \\
\text { INTERPESSOAL }\end{array}$ & $\begin{array}{l}\text { PREOCUPAÇOEES } \\
\text { CONSCIENTES }\end{array}$ & $\begin{array}{l}\text { ESTILO } \\
\text { COGNITIVO }\end{array}$ \\
\hline Pré-Social & Eu-0 & & Autista & & \\
\hline Simbiotico & Eu-1 & & Simbiótico & $\begin{array}{l}\text { Próprio vs. Não } \\
\text { próprio }\end{array}$ & \\
\hline Impulsivo & Eu-2 & $\begin{array}{l}\text { Impulsivo, medo de } \\
\text { retaliação }\end{array}$ & $\begin{array}{l}\text { Receptor, } \\
\text { dependente, } \\
\text { explorador }\end{array}$ & $\begin{array}{l}\text { Sentimentos corporais, } \\
\text { especialmente sexuais } \\
\text { e agressivos }\end{array}$ & $\begin{array}{l}\text { Estereotipia, } \\
\text { confusão } \\
\text { conceptual }\end{array}$ \\
\hline
\end{tabular}




\begin{tabular}{|c|c|c|c|c|c|}
\hline Autoprotetor & Eu-delta & $\begin{array}{l}\text { Medo de ser apanhado, } \\
\text { exteriorização de } \\
\text { censura, oportunismo }\end{array}$ & $\begin{array}{l}\text { Cauteloso, } \\
\text { manipulador, } \\
\text { explorador }\end{array}$ & $\begin{array}{l}\text { Autoprotecçåo, } \\
\text { perturbação, desejos, } \\
\text { coisas, vantagem, } \\
\text { controlo }\end{array}$ & \\
\hline Conformista & Eu-3 & $\begin{array}{l}\text { Conformista para com } \\
\text { regras externas, } \\
\text { vergonha, culpa pela } \\
\text { quebra de regras }\end{array}$ & $\begin{array}{l}\text { Pertença, simpatia } \\
\text { superficial }\end{array}$ & $\begin{array}{l}\text { Aparência, } \\
\text { aceitabilidade social, } \\
\text { sentimentos banais, } \\
\text { comportamento banal }\end{array}$ & $\begin{array}{l}\text { Simplicidade } \\
\text { conceptual, } \\
\text { estereótipos }\end{array}$ \\
\hline $\begin{array}{l}\text { Consciencioso- } \\
\text { Conformista }\end{array}$ & $E u-3 / 4$ & $\begin{array}{l}\text { Diferenciação de } \\
\text { normas, objetivos }\end{array}$ & $\begin{array}{l}\text { Consciência do } \\
\text { próprio em } \\
\text { relação com o } \\
\text { grupo, ajuda }\end{array}$ & $\begin{array}{l}\text { Ajustamento, } \\
\text { problemas, razoes, } \\
\text { oportunidades (vagos) }\end{array}$ & Multiplicidade \\
\hline Consciencioso & Eu-4 & $\begin{array}{l}\text { Padrões auto-avaliados, } \\
\text { autocritica, culpa pelas } \\
\text { conseqitências, } \\
\text { objetivos e ideais de } \\
\text { longo prazo }\end{array}$ & $\begin{array}{l}\text { Preocupação pela } \\
\text { comunicą̧̃̃o } \\
\text { intensiva, } \\
\text { responsável, } \\
\text { mútua }\end{array}$ & $\begin{array}{l}\text { Sentimentos } \\
\text { diferenciados, motivos } \\
\text { para o comportamento, } \\
\text { respeito próprio, } \\
\text { realizaçס̄es, traços, } \\
\text { expressão } \\
\end{array}$ & $\begin{array}{l}\text { Complexidade } \\
\text { conceitual, } \\
\text { idéia de } \\
\text { padronização }\end{array}$ \\
\hline Individualista & $\mathrm{Eu}-4 / 5$ & $\begin{array}{l}\text { Adicionar: } \\
\text { Respeito pela } \\
\text { individualidade }\end{array}$ & $\begin{array}{l}\text { Adicionar: } \\
\text { Dependência } \\
\text { percebida como } \\
\text { um problema } \\
\text { emocional }\end{array}$ & $\begin{array}{l}\text { Adicionar: } \\
\text { Desenvolvimento, } \\
\text { problemas sociais, } \\
\text { diferenciação da vida } \\
\text { interior e exterior }\end{array}$ & $\begin{array}{l}\text { Adicionar: } \\
\text { Distinção } \\
\text { entre } \\
\text { processos e } \\
\text { resultados }\end{array}$ \\
\hline Autônomo & Eu-5 & $\begin{array}{l}\text { Adicionar: } \\
\text { Capacidade de lidar } \\
\text { com necessidades } \\
\text { internas conflituosas, } \\
\text { tolerância }\end{array}$ & $\begin{array}{l}\text { Adicionar: } \\
\text { Respeito pela } \\
\text { autonomia, } \\
\text { interdependência }\end{array}$ & $\begin{array}{l}\text { Sentimentos } \\
\text { manifestados } \\
\text { vivamente, integração } \\
\text { do fisiológico e do } \\
\text { psicológico, causação } \\
\text { psicológica do } \\
\text { comportamento, } \\
\text { concepção de papéis. } \\
\text { auto-realização, o } \\
\text { próprio no contexto } \\
\text { social }\end{array}$ & $\begin{array}{l}\text { Aumento da } \\
\text { complexidade } \\
\text { conceptual, } \\
\text { padrōes } \\
\text { complexos, } \\
\text { tolerância pela } \\
\text { ambiguidade, } \\
\text { objetivos } \\
\text { alargados, } \\
\text { objetividade }\end{array}$ \\
\hline Integrado & Eu-6 & $\begin{array}{l}\text { Adicionar: } \\
\text { Reconciliação dos } \\
\text { conflitos internos, } \\
\text { renúncia ao inatingivel }\end{array}$ & $\begin{array}{l}\text { Adicionar: } \\
\text { Valorização da } \\
\text { individualidade }\end{array}$ & $\begin{array}{l}\text { Adicionar: } \\
\text { Identidade }\end{array}$ & \\
\hline
\end{tabular}

Fonte: Loevinger (1982)

\section{A Teoria do Desenvolvimento do Ego de Loevinger e a Autonomia Moral}

A teoria do desenvolvimento do ego apresentada possibilita, no nosso entender, uma compreensão mais lata do fenômeno da autonomia, na perspectiva que nos interessa aprofundar, e que é a da autonomia moral.. Relativamente às perspectivas anteriormente apresentadas, este quadro conceptual permite: (a) relacionar a construção da autonomia com a experiência subjetiva que o sujeito vai fazendo de si mesmo, associada à vivência da sua identidade emergente (considerando, como tal, a vertente emocional de uma forma originária); (b) compreender a construção da autonomia numa dialética de se- paração-inclusão (e não apenas numa dinâmica de separação-individuação).

\section{Relação entre autonomia e identidade}

O desenvolvimento do ego, na teoria de Loevinger, pressupõe uma experiência do sujeito, que conhece diferentes padrões ao longo de um contínuo desenvolvimental. A emergência da autonomia acompanha, assim, o aparecimento de formas diferentes de identidade (Blasi, 1988).

Em rigor, só podemos falar da emergência da autonomia moral a partir do Grau-3/4 de Loevinger. No Eu-3/4, o sujeito caracteriza-se pela capacidade de se demarcar relativamente às normas e padrões 
do grupo, começando a determinar os seus próprios valores, no sentido de encontrar soluções contrárias ou alternativas à maioria. $\mathrm{O}$ fundamento disto reside, precisamente, numa nova consciência de si mesmo. A partir deste estágio, o eu passa a se definir e a se vivenciar como uma totalidade, caracterizada por traços interiores psicológicos e não mais por ações ou características exteriores. Para Blasi (1988) este estágio corresponde a um tipo de identidade observada.

Desde o estágio consciencioso (Eu-4) de Loevinger, a identidade deixa de ser vivida como algo de existente, de previamente dado e acessível à observação, passando a ser entendida como prolongada na ação e na administração de si mesma. O dever e a responsabilidade tornam-se categorias centrais neste estágio. Assiste-se, assim, a uma consolidação da autonomia, na medida em que o indivíduo não se sente apenas a fonte intencional das suas ações, como acontecia na fase anterior, mas sente também que investe nelas, projetando a sua identidade.

A partir do estágio autônomo de Loevinger (Eu-5), o sujeito caracteriza-se pela perda dos objetivos e ideais claros, característicos do estágio anterior e nos quais se fundava a sua unidade. Esta passa a ser concretizada através de uma perspectiva mais lata de si e do mundo, um sentido de abertura e de procura. Este padrão de vivência corresponde, pois, à autenticidade.

Em termos de autonomia, esta vivência da identidade como autenticidade caracteriza-se pelo esforço de quebrar os constrangimentos estreitos dos estereótipos sociais e das verdades aceitas, com vista à procura de uma verdade mais geral e a uma identificação com a humanidade universal. Este estágio corresponde à superação de uma perspectiva deontológica, mediante a adoção de uma perspectiva teleológica, que gere as exigências de universalidade através de uma sabedoria prática, cuja marca distintiva é a solicitude por si e pelos outros.

Separação e inclusão. A psicologia do desenvolvimento tendeu a equacionar o desenvolvimento individual como o resultado de um movimento que procederia da dependência para a autonomia, possibilitando a consideração de aspectos cada vez mais latos da experiência pelo sujeito. Segundo Josselson (1988), este paradigma da separação-individuação dominou a compreensão do desenvolvimento.
Também neste aspecto parece-nos crucial a contribuição da teoria do desenvolvimento do ego de Loevinger. $O$ alcance da autonomia, enquanto manifestação da maturidade do sujeito, deve ser entendida como um equilíbrio entre aqueles dois movimentos. No estágio autônomo de Loevinger, o sujeito reconhecendo a inevitabilidade da autonomia dos outros, apercebe-se, simultaneamente, da necessidade de uma dependência emocional.

Esta conceituação da autonomia, como resultado de uma dialética de separação-inclusão tem consequiências ao nível da compreensão do desenvolvimento das mulheres. Considerou-se que, dado o desenvolvimento dos indivíduos do gênero feminino ser feito sob a dominância da interpessoalidade e empatia, o alcance da autonomia, enquanto individuação, estava vedado às mulheres. Foi com base na constatação de que as mulheres constroem a realidade de forma diferente dos homens, definindose num contexto inter-relacional, que Gilligan (1982) criticou o modelo de Kohlberg, considerando-o enviesado, isto é, vinculado apenas às coordenadas do desenvolvimento masculino. A consideração da autonomia, à luz das teorias do desenvolvimento do ego apresentada, reduz esta questão a uma falsa questão (Thorne, 1993). O desenvolvimento deve ser entendido numa espiral de separação-inclusão em ambos os gêneros e a autonomia, enquanto meta do desenvolvimento, é, ela mesma, o resultado de uma integração da dependência e independência. Apontando para uma compreensão mais lata do desenvolvimento, a teoria de Loevinger sugere que à importância concedida à descentralização social, enquanto dimensão principal do desenvolvimento moral, deve ser acrescentada a importância do desenvolvimento de uma diversidade de competências perceptivas, empáticas e relacionais (na linha do que tem, de resto, sido defendido por Gilligan, e Nodding, entre outros autores ${ }^{3}$ ).

\section{Conclusão}

A teoria do desenvolvimento do ego de Jane Loevinger, fruto do diálogo entre a tradição cognitivodesenvolvimental e a tradição psicanalítica, integra

${ }^{3}$ Sobre a importância da complementaridade entre as duas abordagens, cf. Marques (1997) e Puka (2000) 
o ponto de vista participativo na abordagem estrutural do desenvolvimento. A estruturação da realidade física e social a que correspondem os diversos estágios é acompanhada por uma reestruturação dialética da própria unidade originária (o sujeito) com a qual o sujeito se identifica.

Neste contexto, o processo de construção da autonomia moral é entendido como equivalendo a um movimento dialético de separação-inclusão (e não de separação-individuação) na medida em que o desenvolvimento e a diferenciação implicam um espaço de integração, baseado na reciprocidade e no incentivo dos outros. Em termos educativos, esta concepção de autonomia, enquanto expoente da maturidade moral, implica a combinação de práticas relacionadas com o desenvolvimento dos princípios da justiça com práticas incentivadoras das relações interpessoais.

\section{Referências Bibliográficas}

Blasi, A. (1988). Identity and the development of the self. Em D.K. Lapsley \& F.C. Power (Orgs.), Self, ego, and identity (pp. 226-241). Nova Iorque: Springer-Verlag.

Blasi, A. (1993). The theory of ego development and the measure. Psychological Inquiry, 4,17-55.

Gilligan, C. (1982). In a different voice. Cambridge: Harvard University Press.

Hauser, S. (1993). Loevinger's model and measure of ego development: A critical review II. Psychological Inquiry, 4, 23-30.

Josselson, R. (1988). The embedded self: I and Thou revisited. Em D.K. Lapsley e F.C. Power (Orgs.), Self, ego, and identity (pp.91-106). Nova Iorque: Springer-Verlag.

Kegan, R. (1982). The evolving self. Cambridge: Harvard University Press.

Kohlberg, L. (1981). Essays on moral development, Vol. 1. The philosophy of moral development. São Francisco: Harper \& Row.

Kohlberg, L. (1982). The child as a moral philosopher. Em J.K. Gardner (Org.), Readings in de- velopmental psychology (pp. 391-399). Boston: Little Brown and Company.

Loevinger, J. (1982). Ego development ( $4^{\mathbf{a}}$ ed.). São Francisco: Jossey-Bass Publishers.

Loevinger, J. \& Wessler, R. (1970). Measuring ego development: Vol. 1. São Francisco: Jossey-Bass Publishers.

Marques, R. (1997). A justiça, a preocupação pelos outros e a bondade: pode a escola passar sem elas? Em M.F. Patrício (Org.), A escola cultural e os valores (pp. 353-363). Porto: Porto Editora.

Moessinger, P. (1989). La psychologie morale. Paris: Presses Universitaires de France.

Noam, G. (1993). Ego development: True or false? Psychological Inquiry, 4,43-48.

Piaget, J. (1932). Le jugement moral chez l'enfant. Paris: Presses Universitaires de France.

Piaget, J. (1975). A teoria de Piaget. Em P. Mussen (Org.), Manual de psicologia da criança (pp. 71115). S.Paulo: EPU

Puka, B. (2000). Inclusive moral education: A critique and integration of competing approaches. Em M. Leicester, C. Modgil \& S. Modgil (Orgs.), Education, culture and values, Vol.4: Moral education and pluralism (pp. 131-148). London: Falmer Press.

Selman, R. (1980). The growth of interpersonal understanding. São Diego: Academic Press Inc.

Thorne, A. (1993). On contextualizing Loevinger's stages on ego development. Psychilogical Inquiry, 4,53-55.

Obs: Este artigo retoma parcialmente o capítulo de revisão da literatura da dissertação de mestrado ' $O$ diplomado do ensino secundário e a autonomia de valores num quadro de maturidade global'. Lisboa: UCP (1996) 